Research Article

\title{
Effect of Computer-Assisted Instructions on the Students about Rocking In the Chair during First Stage of Labour
}

\author{
Archana Selvan', N Kumar ${ }^{2}$ \\ ${ }^{1}$ Professor \& Principal, RKDF College of Nursing, Bhopal, Madhya Pradesh, India. \\ ${ }^{2}$ Department of Nursing, Sarvapalli Radhakrishnana University, Bhopal, Madhya Pradesh, India. \\ DOI: https://doi.org/10.24321/2348.2141.201904
}

\section{I $\quad \mathbf{N} \quad \mathbf{F} \quad \mathbf{O}$}

\author{
Corresponding Author: \\ Archana Selvan, RKDF College of Nursing, Bhopal, \\ Madhya Pradesh, India. \\ E-mail Id: \\ archanaselvan6@gmail.com \\ Orcid Id: \\ https://orcid.org/0000-0003-3603-9460 \\ How to cite this article: \\ Selvan A, Kumar N. Effect of Computer-Assisted \\ Instructions on the Students about Rocking In the \\ Chair during First Stage of Labour. Trends Nurs \\ Adm Edu 2019; 8(1): 18-24.
}

Date of Submission: 2019-05-23

Date of Acceptance: 2019-06-14

\section{$\begin{array}{llllllll}\mathbf{A} & \mathbf{B} & \mathbf{S} & \mathbf{T} & \mathbf{R} & \mathbf{A} & \mathbf{C} & \mathbf{T}\end{array}$}

Upright positions allow gravity to increase the intensity of the contractions during labour naturally, while minimizing the discomfort felt. Upright positions include standing, walking, rocking, sitting on a bed and chair, leaning against a wall, dangling in someone's arms, leaning over the back of a chair.

The present study was conducted to assess the effect of computer assisted Instructions on knowledge gain of students on non-pharmacological interventions during first stage of labour. An experimental design was chosen with pre-test and post-test of experimental and control group. The sample size was 60 B.Sc Nursing IV Year students divided into two groups as 30 in experimental and 30 in control group. The tools used for conducting the study included demographic data, self structured questionnaire to assess knowledge of experimental and control group. The experimental group was given computer assisted Instructions as an intervention and the control group was used for comparison only without interventions. The data were analyzed with statistics and unpaired t-test was done. The study clearly shows that there was a significant gain in knowledge of students in experimental group with computer assisted Instructions on non-pharmacological interventions during first stage of labour which is safe and improves maternal and fetal outcome. Therefore the patients can be benefited with improved knowledge and practices of midwives on non-pharmacological interventions. In this study rocking as an intervention in a rocking chair during first stage of labour from $3 \mathrm{cms}$ dilatation to $6 \mathrm{cms}$ dilatation was taught to the students with an aim and to promote it in to practice in clinical area in future.

Keywords: Effect, Computer Assisted Instructions, Rocking in the Chair, First Stage of Labour

\section{Introduction}

Pregnancy is a time of great physical and emotional change, we nurture the new life growing inside the womb and giving birth is a highlight in a woman's life. The support and care they receive during this time is very critical. The experience

Trends in Nursing Administration \& Education (ISSN: 2348-2141) 
of labour pain is a complex, individual and multifaceted response to sensory stimuli generated during child birth. ${ }^{1}$

History reveals that labouring women have always walked, moved and changed their position spontaneously to make themselves more comfortable. In midwifery model of care, the midwife often suggests specific body positioning and use of devices aiding to relaxation during delivery. Based on many clinical trials it is proved that relaxation exercises, changing positions and movement during first stage of labour has brought better maternal and fetal out come. ${ }^{2}$

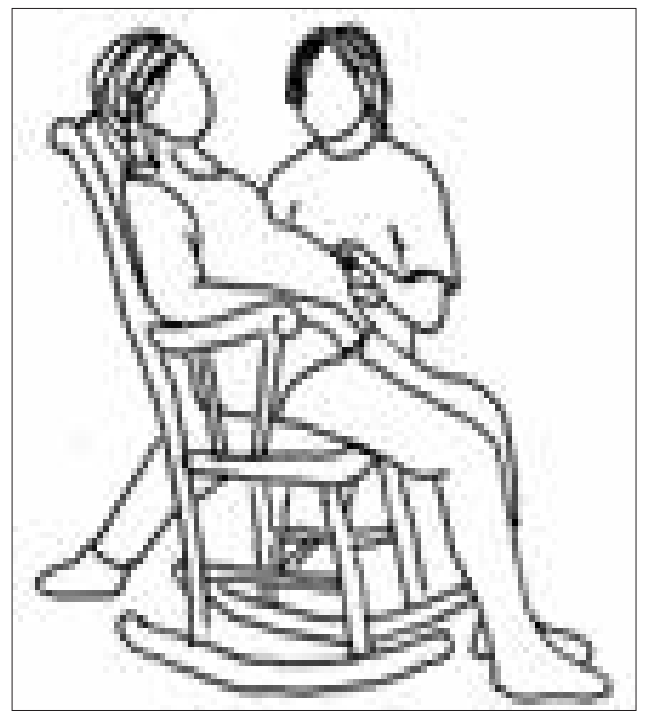

Rocking Chair

Upright positions allow gravity to increase the intensity of the contractions naturally, while minimizing the discomfort felt. Upright positions include standing, walking, leaning against a wall, dangling in someone's arms, slow dancing or leaning over the back of a chair. ${ }^{3}$

Combining movement with positions can help and encourage a productive labour while helping to cope with the stress and pain of contractions. Walking, swaying and rocking hips are especially helpful because they make it easier for the baby to move through the pelvis. ${ }^{3}$

Specific movements can be used to achieve specific goals. For example, pelvic rocking can reduce the pain of a sore back. Understanding which movements and positions help to encourage specific outcome that can help labour move problem free and as quickly as possible. Rocking in a rocking chair during first stage of labour can facilitate fetal decent in lower uterine segment in turn reducing length of labour and minimizing chances of complications which occur due to delayed labour. ${ }^{4}$

Client in first stage of labour with $3 \mathrm{cms}$ cervical dilatation is advised to sit comfortably and rock in a rocking chair and rocking will continue up to $6 \mathrm{cms}$ of cervical dilatation only, as per the direction given below:

Step I-With weight planted on left foot use the right foot to step forward, rocking your weight towards the right foot.

Step II: Then rock weight back on the left foot (recover).

Step III: Step right foot backward.

Step IV: Rocking weight onto left foot then recover weight back onto right planted foot.

Step V: Recover as normal sitting position in the chair and repeat the same steps as earlier for 10 minutes then rest for 10 minutes. 3 such sets should be repeated hourly till $6 \mathrm{cms}$ of dilatation. The picture is shown below. ${ }^{5}$

\section{Problem Statement}

Assess The Effect of Computer Assisted Instructions on Knowledge of B.Sc Nursing Students on Rocking In a Rocking Chair During First Stage of Labour Among Primi Parturient Mothers of Selected Hospitals at Bhopal, (M.P.).

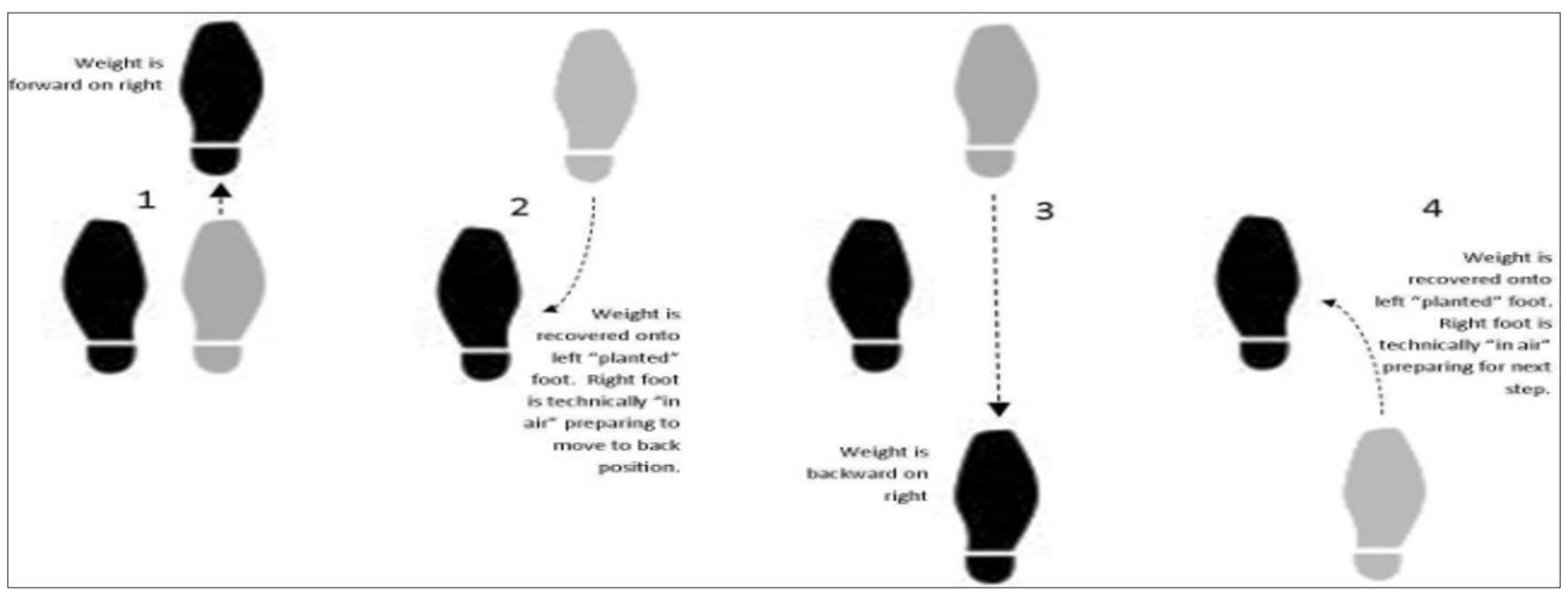

Figure 2.Steps to rock in rocking chair during first stage of labour 


\section{Objectives of the Study}

The objective of the study:

- Assess the knowledge score of B.Sc. Nursing Students in experimental group and control group on the rocking in a chair as a non pharmacological interventions during first stage of labour among primi-parturient mothers.

- Prepare power point presentation as Computer Assisted Instructions (CAI) program on the rocking in a rocking chair during first stage of labour among primi parturient mothers.

- Assess the effects of Computer Assisted Instructions (CAI) on knowledge of the experimental group regarding rocking in a chair during first stage of labour among primi parturient mothers.

- Compare the knowledge of experimental and control group regarding the rocking in a chair during first stage of labour among primi parturient mothers.

\section{Null Hypothesis}

$\mathbf{H}_{1}$ : There will be no significant difference in the knowledge score of the B.Sc. Nursing Students of the experimental group with computer assisted instructions on the rocking in a chair during first stage of labour among primi parturient mothers.

$\mathbf{H}_{2}$ : There will be no significant difference in the knowledge score between control and experimental group after computer assisted instructions to experimental group regarding the rocking in a chair during first stage of labour among primi parturient mothers.

$\mathbf{H}_{3}$ : There will be no significant association between experimental and control group with their selected demographic variables on the rocking in a chair during first stage of labor among primi parturient mothers.

\section{Methods}

Evaluative research approach was adopted in the study to assess the effectiveness of computer assisted instructions on gain of knowledge regarding rocking in a chair during first stage of labour among primi parturient mothers.

Rocking means swinging movement while sitting in a rocking chair, taught to primi parturient mothers during first stage of labour between cervical dilatation of 3-6 cms.

A true experimental research design with pre-test and posttest of experimental and control group was used during the study. The study was conducted at selected colleges of Nursing at Bhopal, Madhya Pradesh, India for 6weeks. The samples were 60 B.Sc. nursing IV year students who fulfilled the inclusion criteria sampling criteria out of that 30 were taken in the experimental group and 30 were taken as control group. In this study, a total of 60 B.Sc. nursing IV year students were selected by systematic random technique.

\section{Variables under Study \\ Independent Variable}

The power point presentation as computer assisted instructions on rocking in a chair during first stage of labour among primi parturient mothers.

\section{Dependent Variable}

Knowledge is a dependent variable which is dependent on computer assisted instructions.

\section{Demographic Variables}

Age, Religion, Academic qualification and Source of knowledge about rocking in a rocking chair in first stage of labour.

Sample: IV Year B.sc Nursing Students.

Sample size: Total 60 (30 each in Control and experimental group).

\section{Criteria for Sample Selection}

\section{Inclusion Criteria}

- B.Sc. Nursing IV Year Students willing to participate in the study.

\section{Exclusion Criteria}

- B.Sc. Nursing IV Year Students writing supplementary exams.

Duration of Study: 6 weeks.

\section{Development and Description of the Tool}

The investigator used the following steps for preparation of the tools for the study:

- Extensive review of literature The investigator did an extensive review of related literature from books, journals, manuals; reports published researches, newspapers and internet to develop study instruments.

- Consultation with experts from the field of study.

- Preparation of the final draft of the tools after testing reliability and validity of the tools.

Section A: Demographic variables

Section B: Self constructed Questionnaire with thirty items to assess knowledge of B.Sc. Nursing IV Year Students on rocking in a chair during first stage of labour.

Section C: Preparation of power point presentation as Computer Assisted Instructions on rocking in a chair during first stage of labour as a non-pharmacological Intervention on experimental group.

\section{Scoring Procedure}

Each question had 04 options from which the sample had 
to choose only 01 (one) correct answer. The right answer was scored as 01 and the wrong option was scored as zero. The scoring was interpreted as below:

- Inadequate knowledge-score less than 50\%

- Moderate knowledge-score between 51-74\%

- Adequate knowledge-more than $75 \%$

\section{Intervention}

The computer assisted instructions (PPT) of 45 minutes duration was shown to B.Sc Nursing IV Year Students of the experimental group and the control group did not receive the intervention i.e. Computer assisted instructions and they continued with college routine as earlier.

\section{Method of Data Collection}

An informed written consent was taken from the samples and the permission to conduct the study was obtained from the authorities. The data was collected in the following phases.

Phase 1: The structured questionnaire consisting of 30 items was administered on B.Sc Nursing IV Year Students of experimental and control group to assess the pre-test knowledge score on rocking in a chair during first stage of labour.

Phase 2: The computer assisted instructions session of 45 minutes was carried out for B.Sc Nursing IV Year Students of the experimental group while the samples in the control group continued with the normal routine of their college.
Phase 3: The same questionnaire was again administered on seventh day for both experimental and control group.

\section{Statistical Analysis}

Data was organized then analyzed for the knowledge of students on rocking in a chair during first stage of labour among primi-parturient mothers. The data were analyzed in terms of frequency, percentage, mean and standard deviation. Unpaired t-test is used to test the significant difference in the knowledge between the experimental and the control group.

\section{Findings}

The demographic variables of B.Sc. Nursing IV Year Students are given in Table as below:

It is observed from in table 1 , that in experimental group a majority of B.Sc. Nursing IV Year Students 25 (83.33\%) belongs to $21-24$ years of age, 05 (16.66\%) were between $25-29$ year old and no student was found in the age group of 30 and above.

In control group 22 (73.33\%) students belong to $21-24$ years of age, then 8 (26.66\%) students were between $25-29$ year of age and no students was found to be 30 and above in age group.

In religion a majority of Students that is $17(56.66 \%)$ were Hindus, 04 (13.33\%) students were Muslims and 9 (30\%) Students were Christian in the experimental group.

Table I.Frequency and Percentage distribution of subjects as per age, religion, academic qualification, source of knowledge

$\mathrm{N}=60$ (Experimental-30 \& Control-30)

\begin{tabular}{|c|c|c|c|c|c|}
\hline \multirow{3}{*}{ Characteristics } & \multirow{3}{*}{ Category } & \multicolumn{4}{|c|}{ Subjects Group } \\
\hline & & \multicolumn{2}{|c|}{ Experimental } & \multicolumn{2}{|c|}{ Control } \\
\hline & & $\mathbf{N}$ & $\%$ & $\mathbf{N}$ & $\%$ \\
\hline \multirow{3}{*}{ Age Group (in years) } & $21-24$ & 25 & 83.33 & 22 & 73.33 \\
\hline & $25-29$ & 05 & 16.66 & 08 & 26.66 \\
\hline & $30 \&$ above & 00 & 00 & 00 & 00 \\
\hline \multirow{3}{*}{ Religion } & Hindu & 17 & 56.66 & 20 & 66.66 \\
\hline & Muslim & 04 & 13.33 & 03 & 10 \\
\hline & Christian & 09 & 30 & 07 & 23.33 \\
\hline \multirow{4}{*}{$\begin{array}{c}\text { Academic } \\
\text { Qualification }\end{array}$} & $12^{\text {th }}$ standard & 24 & 80 & 25 & 83.33 \\
\hline & B.Sc completed & 01 & 3.33 & 03 & 10 \\
\hline & B.Sc not completed & 04 & 13.33 & 02 & 6.66 \\
\hline & Any other & 01 & 3.33 & 00 & 00 \\
\hline \multirow{3}{*}{ Source of Knowledge } & News Papers \& Magazines & 25 & 83.33 & 25 & 83.33 \\
\hline & Relatives & 05 & 16.66 & 05 & 16.66 \\
\hline & Any other & 00 & 00 & 00 & 00 \\
\hline
\end{tabular}


In control group a majority of B.Sc. Nursing IV Year Students that is $20(66.66 \%)$ were Hindus, $03(10 \%)$ were Muslims and $07(23.33 \%)$ Students were Christians.

In academic qualification a majority of B.Sc. Nursing IV Year Students that is $24(80 \%)$ were 12 standards passed, 01 (3.33\%) had completed B.Sc and 04 (13.33\%) could not complete graduation. 01 (3.33\%) student had done PGDCA in the experimental group.

In control group a majority of B.Sc. Nursing IV Year Students that is $25(83.33 \%)$ were 12 standards passed, $03(10 \%)$ had completed B.Sc. and $02(6.66 \%)$ could not complete graduation.

The source of knowledge for a majority of B.Sc Nursing
Students was news paper and magazines i.e. 25 (33.33\%) in the experimental group and the same was found in control group. Besides 05 (16.67\%) B.Sc. Nursing IV Year Students acquired knowledge on non-pharmacological interventions during labour from their relatives and the same percentage was applicable to control group of B.Sc. Nursing Students.

In pre-test of the experimental group 28 (93.33\%) students had inadequate knowledge and 02 students (6.67\%) had moderate knowledge but after computer assisted instructions on the subject in post-test 04 (13.33\%) of them had demonstrated moderate knowledge whereas 26 (86.67\%) of them had demonstrated adequate knowledge score.

Table 2.Frequency and Percentage distribution of overall knowledge score of experimental and control group

\begin{tabular}{|c|c|c|c|c|c|c|c|c|c|}
\hline & & & & & & & $N=60(E)$ & lents & it \\
\hline \multirow{3}{*}{ S. No. } & \multirow{3}{*}{ Level of knowledge } & \multicolumn{4}{|c|}{ Experimental group } & \multicolumn{4}{|c|}{ Control group } \\
\hline & & \multicolumn{2}{|c|}{ Pre-test } & \multicolumn{2}{|c|}{ Post-test } & \multicolumn{2}{|c|}{ Pre-test } & \multicolumn{2}{|c|}{ Post-test } \\
\hline & & $\mathbf{f}$ & $\%$ & $f$ & $\%$ & f & $\%$ & $f$ & $\%$ \\
\hline 1. & Inadequate $(<50 \%)$ & 28 & 93.33 & - & - & 28 & 93.33 & 27 & 90 \\
\hline 2. & Moderate (51-74\%) & 02 & 6.67 & 04 & 13.33 & 02 & 6.67 & 03 & 10 \\
\hline 3. & Adequate (>75\%) & - & - & 26 & 86.67 & - & - & - & - \\
\hline
\end{tabular}

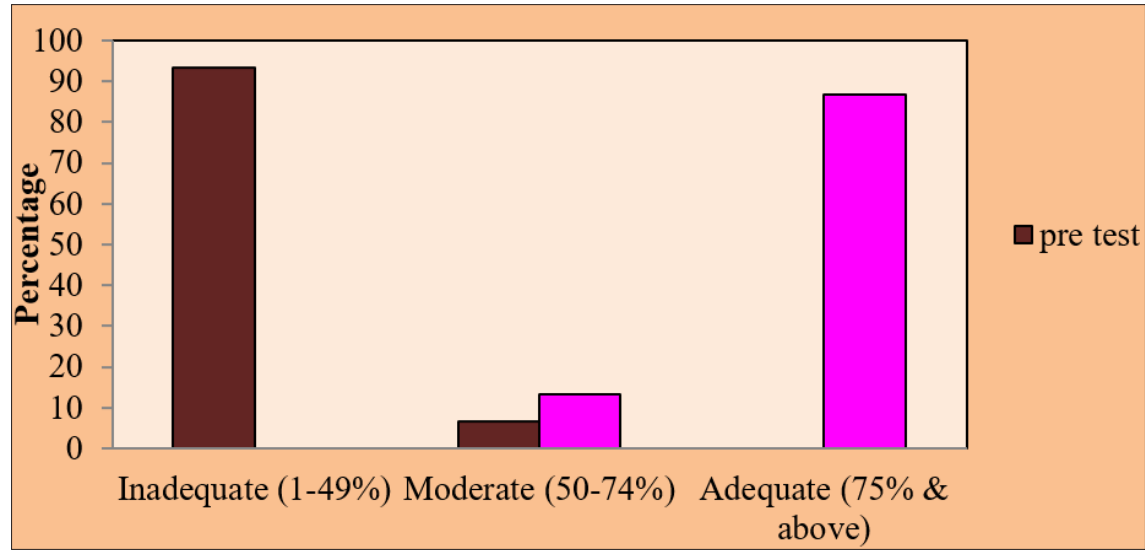

Figure 3.Bar graph showing the level of knowledge of the experimental group

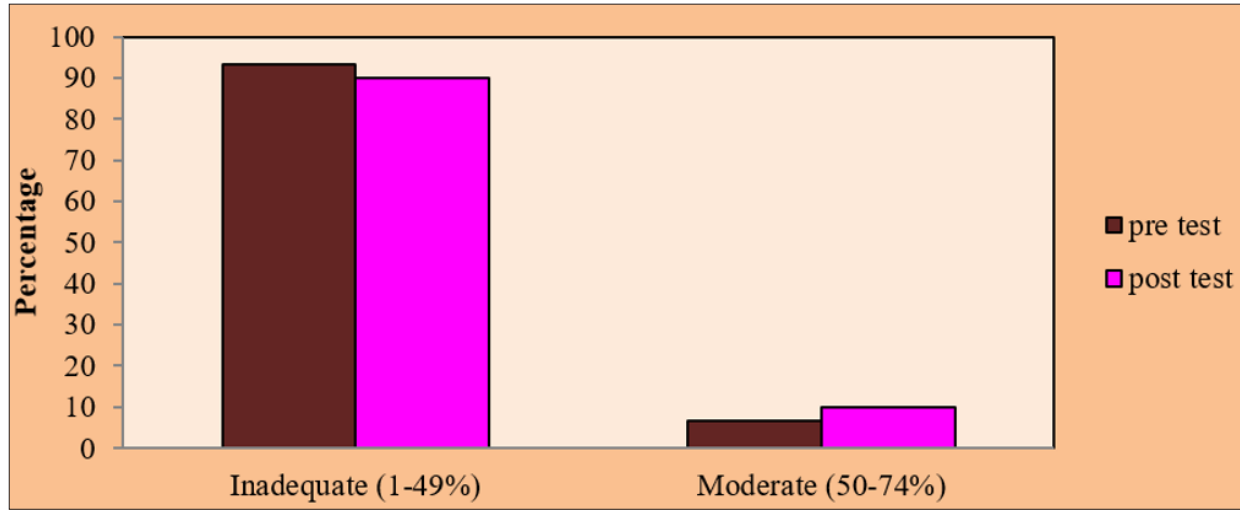

Figure 4.Bar graph showing the level of knowledge of control group 
In the control group a majority of B.Sc. Nursing IV Year Students in pre-test that is $28(93.33 \%)$ had inadequate knowledge score and $02(6.67 \%)$ of them had moderate knowledge score. In post-test 27 (90\%) of them showed inadequate knowledge and $03(10 \%)$ of them had shown moderate knowledge score. significant difference in the knowledge gain between control and experimental group with CAI. The post test revealed that experimental group had demonstrated knowledge gain where as control group didn't demonstrate gain in knowledge after post test.

Table 3.Comparison of overall pre-test and post-test mean, standard deviation, mean difference and paired -'t' value between experimental and control group

$\mathrm{N}=60$ (Experimental -30 \& Control-30)

\begin{tabular}{|c|c|c|c|c|c|c|c|}
\hline \multirow{2}{*}{ S. No. } & \multirow{2}{*}{ Group } & \multicolumn{2}{|c|}{ Mean } & \multicolumn{2}{|c|}{ Standard deviation } & \multirow{2}{*}{$\begin{array}{c}\text { Mean } \\
\text { Difference }\end{array}$} & \multirow{2}{*}{ Paired t-test } \\
\hline & & Pre-test & Post-test & Pre-test & Post-test & & \\
\hline 1. & Experimental & 11.633 & 22.33 & 1.2665 & 1.5 & 10.697 & $1.2(\mathrm{df}=29)$ \\
\hline 2. & Control & 11.466 & 11.33 & 1.3 & 1.1 & 0.136 & $0.46818 \mathrm{df}-29$ \\
\hline
\end{tabular}

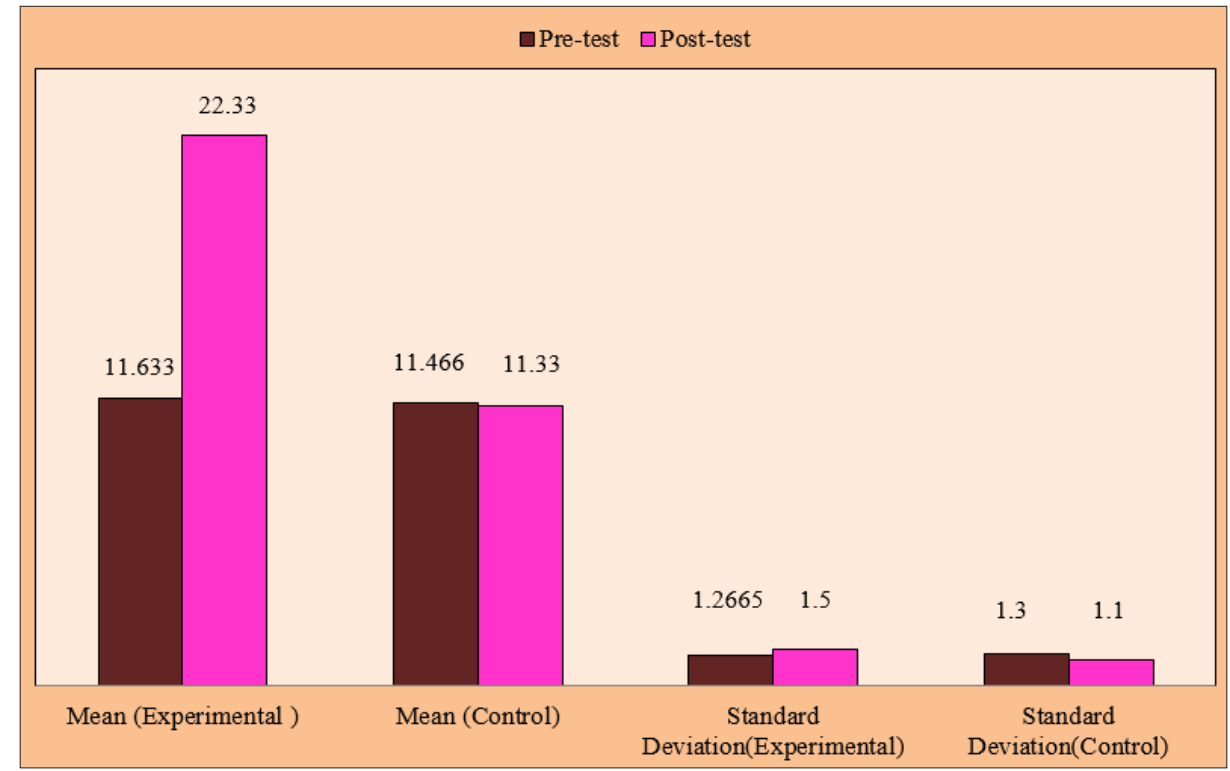

Figure 5.Bar graph showing the comparison of overall pre-test and post-test mean, standard deviation between experimental and control group

Table 3, Shows post test mean of experimental group is 22.33 with standard deviation 1.5 whereas in control group the post test mean is 11.33 and standard deviation is 1.1 . The obtained t- value is 1.2. Since the Calculated Value (CV) is more than Table Value (TV) at the 0.005 levels \& at 29 degree of freedom therefore the null hypothesis is rejected that infers that there is a significant difference with computer assisted instructions on knowledge gain among B.Sc Nursing IV Year Students of the experimental group.

\section{Discussion}

The overall percentage of knowledge of B.Sc Nursing IV Year in experimental group for pre-test was inadequate i.e. $93.33 \%$ and it was moderate for $6.67 \%$ Students. the post test knowledge score increased after computer assisted instructions to $13.33 \%$ to moderate knowledge and $86.67 \%$ Students showed adequate knowledge score. So the hypothesis $(\mathrm{H} 2)$ is rejected that means there was a
The above finding was supported by a study conducted by Abraham $L$ on planned teaching programme on environment health among anganwadi teachers in Manipal. The sampling technique adapted was convenience sampling and the sample size was 54. The research design adopted was one group pre-test post test design. The result of the study found that in the pre-test only $32 \%$ had good knowledge, whereas in the post-test, all $100 \%$ had good knowledge so video assisted teaching was effective for planned teaching programme. $^{6}$

Another study was conducted by Eleazar et al. on effectiveness of planned teaching programme on prevention and early detection of cervical cancer for school teachers of selected schools in Mangalore. Purposive sampling technique was used for the selection of 50 school teachers. The study revealed that the mean knowledge scores (30.68) obtained by the school teachers after conducting planned 
teaching programme was higher than mean pre-test knowledge scores (17.26). There was significant difference between mean post-test and pre-test knowledge scores ( $t 49=26, p<0.05)$. The study concluded that planned teaching programme was an effective teaching method for providing knowledge to school teachers. ${ }^{7}$

The present study has demonstrated a marked gain in knowledge after CAT this is supported by an experimental study, conducted by Souza D et al. on effectiveness of planned teaching programme on pre-eclampsia for primigravida women in a selected community at Mangalore. The study revealed that there was a significant difference $(t(29)=3.66, p<0.001)$ between pre-test and post-test knowledge scores of the respondents indicating significant increase in knowledge after planned teaching programme. ${ }^{8}$

\section{Conclusion}

The study showed Computer Assisted Teaching (CAT) had increased the knowledge of students regarding non pharmacological intervention i.e. rocking in the rocking chair during first stage of labour. A lot of research literature regarding it is also available on benefits of rocking in sitting position and the role of gravity in foetal descent into lower uterine cavity thereby facilitating labour thus this knowledge can be utilized into practice as a non pharmacological interventions to reduce length of labour and it will also help in reducing pharmacological interventions and its side-effects on mother and foetus.

\section{Conflict of Interest: None}

\section{References}

1. Miquelutti MA, Cecatti JG, Siani Morais S, et al. The vertical position during labor: pain and satisfaction. Revista Brasileira de Saúde Materno Infantil 2009; 9: 393-398.

2. Roberts JE, Mendez-Bauer C, Wodell DA. The effects of maternal position on uterine contractility and efficiency. Birth 1983; 10: 243-249.

3. Williams RM, Thorn MH, Studd JWW. A Study of the benefits and acceptability of ambulation in spontaneous labour. British Journal of Obstetrics and Gynaecology 1980; 87: 122-126.

4. MIDIRS. Positions in labour and delivery. Informed choice for professionals leaflet Bristol: MIDIRS. 2008.

5. Step of the Week: Rocking Chair. 2013. Available from: https://linedance4you.wordpress.com/2013/04/10/ step-of-the-week-rocking-chair/.

6. Abraham L. Planned Teaching on Environmental Health. 2009; C(6). Available from http://www.tnaionline.org/ june-09/2.htm.

7. Eleazar, Christina. Effectiveness of planned teaching pro-gramme on prevention and early detection of cervical cancer for school teachers of selected schools in Mangalore. 2007. available from http://hdl.handle. net/123456789/1416.

8. Souza D, Lolitha. Effectiveness of planned teaching pro-gramme on pre-eclampsia for primigravida women in select-ed community at Mangalore. Obstetrics and Gynecological Nursing. Available fromhttp://hdl. handle.net/123456789/1443. 